\title{
REAL LIFE’ IN EVERYDAY AND ACADEMIC MATH: ANALYZING WAYS OF TEACHING COMPARISON OF NUMBERS IN SENIOR PRIMARY MATHEMATICS EDUCATION
}

\author{
Frieda N. Hakadiva-Vatileni ${ }^{1 *}$ \\ *1 University of Namibia, HP Campus, fvatileni@unam.na
}

*Corresponding Author: -

This paper draws on the author's experience that is based on teaching practices of Mathematics Education students. Mathematics Education students consist of school mathematics teachers who are already in the teaching field, and are currently upgrading their qualifications, and student teachers who are currently training to became mathematics teachers at the University of Namibia. These student teachers used four different approaches to teach comparison of numbers at senior primary level (Grade5 -7). School mathematics teachers who are already in the teaching field are observed while conducting their microteaching lessons during School-Based-studied (SBS). Student teachers who are currently training to become mathematics teachers at the University of Namibia were observed while giving their Microteaching lessons to fellow trainees. Data from these observations is used to indicate that contexts that teachers incorporate into the mathematics may not necessarily be institutionalized everyday activities. Secondly, these observations are used to challenge the assumption that: (1) individual teachers are always able to design teaching contexts that draw on every day, for mathematics learning, (2) Teachers are able to predict for their students, how mathematics should be learnt through the use of everyday contexts. In analyzing teacher utterances, I draw from Paul Dowling's notion of recontextualisation, as well as his language of description, that is used to describe school mathematics texts.

\section{(ㄷ) (\$) (1)}




\section{INTRODUCTION}

School mathematics teachers were observed while teaching students at their respective schools during a School-Basedstudy (SBS) program. Student teachers were observed while conducting Microteaching lessons in mathematics module of Mathematics education 1A at the University of Namibia. Both taught the same topic of comparing of numbers.

The data challenges the view that by local contextualization and application of mathematics to everyday life, younger learners will understand and appreciate the uses of mathematics. It also challenges the idea regarding the responsibility that solely rest on individual mathematics teachers to design suitable contexts for their learners. The idea states that "where textbooks can only give general examples, it is up to the teacher to use and include local examples by developing appropriate worksheets and exercises" (Ministry of Education [MoE], 2010a, p. 3).

The aim is not to argue against use of real-life contexts in learning mathematics. However, it is to argue against the idea that (1) mathematics teachers can predict for their students how mathematics should be learnt using contexts based on real life, (2) mathematics teachers are able to determine what 'real life' for mathematics learning means, and that (3) they can, or are always able to design contexts that are meaningful and appealing to their students learning of mathematics. The paper also raise crucial questions as to whether individual school mathematics teachers can design suitable contexts for Mathematics learning, and whether they can always help their students with the mathematics that students need in their everyday lives. First, I look at examples of the claim that incorporation of the everyday into the mathematics classroom is a desirable aspect from the Namibian national policies: the national curriculum as well as from the Namibian mathematics syllabus. Secondly, due different expressions that several authors used to refer to the idea of linking mathematics and students' everyday experiences, I also highlighted that it is not easy to find a comprehensive term that subsumes all the terminologies and phrases that are used in literature.

\section{Promotion of academic - everyday relationship in the mathematics curriculum}

The National Curriculum for Basic Education and the mathematics syllabi for Upper Primary and Junior Secondary education (Ministry of Basic Education Sport and Culture [MBESC], 2008; Ministry of Education [MoE], 2010a, 2010b, 2015) indicate that in Namibia, the teaching and learning of mathematics is valued in its own right for promoting access to advanced and specialised mathematics knowledge. However, this is not the only goal of Namibia's compulsory mathematics education. In terms of teaching contents, these policy documents announce the need to cross borders, not only between different school subjects but also between academic mathematics and everyday knowledge. In particular, in justifying the need to summon the everyday to the mathematics classroom, the National Curriculum for Basic Education states, "we are situated in a

natural and cultural context with which we interact, which affects us and which we draw upon to construct understanding" (MBESC, 2008, p. 28). The document stresses that people learn through and by experiencing things, by reflecting on them, and that it is by reflecting on what has been experienced that the learner's understanding grows.

Furthermore, MBESC (2008, pp. 29-30) declares that if learners are taught and learn by rote memorisation, they forget soon. However, if students are taught in a way which builds on what they already know and have experienced, and relate new knowledge to the reality around them, they tend to realize that learning in school can be meaningful. The position of this policy document to discourage rote learning is a sign of moving away from what in the past has been called teaching that emphasises procedures.

In addition, the syllabi for Upper Primary acknowledge that "mathematics is a powerful language, which provides access to viewing the world" (Ministry of Education [MoE], 2010a, p. 1). This statement appears to hail not only the utilitarian aspect of mathematics but also promotes mathematics as an indispensable tool in understanding the world around people. Furthermore, outlining the general aims of teaching mathematics in Namibian schools, this syllabus reveals that the aim of mathematics teaching is to develop the students' competency in applying mathematics in the contexts of everyday situations and of other school subjects. This aspiration is expressed as follows:

The aims are to enable students to develop their ability to apply mathematics in the contexts of everyday situations and of other subjects that they may be studying (MoE, 2010b, pp. 1-2).

This statement introduces another aim - that of developing a set of skills of applying mathematics in other contexts. However, this document does not seem to highlight or specify, how the idea of applying mathematics should be enacted in the classroom. Another statement found in the mathematics syllabus which expands on the meaning of relationships between mathematics and other practices or student's everyday experience. The statement reads:

Mathematics is a universal language; it is only by local contextualization
and application that younger learners will understand and appreciate the
uses of mathematics. Where textbooks can only give general examples, it is
up to the teacher to use and include local examples by developing
appropriate worksheets and exercises $(M o E, 2010 b, p .3)$.

The syllabus appear to assume that relating school mathematics to students' everyday experiences is beneficial to student in terms of learning mathematics, meaning-making, and appreciating the usefulness of mathematics. As a way of realising a school mathematics curriculum that makes mathematics meaningful for learners, the syllabus suggests that by 
application and local contextualisation, this goal can be achieved. This benefit is also highlighted in the revised mathematics syllabus for Senior Primary. The description of mathematics in the new Namibian Senior Primary mathematics Curriculum, entails both epistemological (what mathematics is) and pedagogical (how mathematics should be taught) position. The new syllabus states:

Mathematics has its own specialised language that uses symbols and notations for describing numerical, geometric and graphical relations. Mathematical ideas and concepts build on one another to create a coherent whole. Mathematics is a purposeful activity in the context of social, political, technological and economic goals and constraints. (Ministry of Education [MoE], 2015, p. 1).

Furthermore, it states:

\begin{abstract}
"Mathematical problems should always be exemplified in a context which is meaningful to the learners" and "learners' prior knowledge needs always to be elicited before commencing with a new topic (Ministry of Education [MoE], 2015, p. 4).
\end{abstract}

The epistemological position, in the first section of the quote foregrounds mathematics as a unique and distinct entity. The pedagogical position, in the second quote, addresses the teaching approach. It invites the approach to mathematics teaching which matches with that of a realistic approach. Thus, "whilst mathematics remains a uniquely distinct entity, the non-mathematical everyday realities may be used as platforms to access it" (Godfrey. Sethole, 2004, p. 18). Both epistemological and pedagogical positions are vital aspects of mathematics teaching and learning. Hence, the declaration of the general aims of teaching mathematics in Namibian schools and the pronouncement in the two-statement cited above suggest a teaching approach which makes mathematics-everyday relationships in the classroom an important aspect to reflect on.

\title{
Terminology consideration
}

It is not easy to pin down the idea of linking mathematics and students' everyday experiences. This is due different expressions different authors used to refer to the same aspect. In this paper, the phrase 'incorporating the everyday' is used due to lack of a better generic term that would subsumes a range of terms and phrases used in mathematics education, which are also expressed from different theoretical perspectives. For instance, in an attempt to derive a framework for designing word problems, Palm (2006, p. 42) referred to mathematics-everyday relationship as

"including the out-of-school world in mathematics education" or the "simulation' of real-life situations through mathematics word problems. Describing the types of real life contexts summoned by teachers, (Godfrey. Sethole, 2004, 2005) discussed mathematics-everyday relationship in terms of recruiting authentic/inauthentic and far/near contexts. In his discussion, Sethole (2004, p. 18) used words such as 'summoning or incorporating the everyday in the mathematics'. The mathematics-everyday relationship is also discussed in terms of horizontal and vertical mathematisation, and their functions (Jablonka, 2008; Treffers, 1987). In his discussion of the asymmetry of the mathematics-everyday relationship, Dowling $(1998,2007)$ used terminologies such as casting a gaze, pushing, and fetching other practices. All these terminologies imply summoning of the everyday into the mathematics classroom

The term 'everyday' needs unpacking as well since it has different connotations. Arcavi (2002, p. 13) examined the concept of “everydayness' and suggest that this term could yield different meanings especially when the question of "every day for whom" is asked. Arcavi proposed that everyday depends on the context and the practice within which the mathematics task takes place. This is due to the idea that, "because of the context, the activity may not be recognized as one that is mathematical" (de Abreu \& Crafter, 2016, p. 399). Discussing difficulties faced by students due to the way recontextualisation works in a mathematics class, Jablonka $(2008$, p. 7) used the term 'everyday' as 'an abbreviation for the for everyday practices that consist of common activities, in which people are involved in family, peer group, community or in some semi-skilled jobs that do not require specialised formal training". Jablonka's use and description of the term everyday clarified what could be defined as the students' everydayness in this paper.

\section{Theoretical considerations}

To find a well-developed and comprehensive language to describe the incorporation of the everyday or students' real life experiences in a mathematics is a challenge. The endeavour to develop coherent framework to help make sense of this task has been an attempt of some researchers. For example, reflecting on the type of considerations to be summoned when engaging mathematics items that incorporate the everyday, Sethole $(2004,2005)$ derived a framework in which he described recruited contexts in terms of authentic/inauthentic and far/near contexts. The framework was derived from the types of real life contexts summoned by mathematics teachers in the classroom.

In another attempt, recognizing that mathematics tasks or items which incorporate the everyday are not homogeneous, and that they could conceal different types and distinctions that might exist among them, Dowling (1998) offered a useful languages by which these differences can be identified. Dowling (1998) used two aspects to describe mathematics items. One is the mode of expression and the nature of contexts (the content) drawn in. The mode of expression implies how strong or weakly classified the item is in terms of language used, as well as inserted mathematics signs or inferences), while the nature of contexts or content suggest (what is being referred to, and whether the context recruited renders itself 
mathematical or nonmathematical). Items which have a highly classified mode of expression are the one that communicate information in "unambiguously mathematical" terms (Dowling, 1998, p. 135). These tasks can either draw from mathematics contexts or from the everyday, and are labelled either as esoteric or descriptive domain. Items which have a weak classified mode of expression are the one that communicate information using nonmathematical expressions. Similarly, these items may draw from mathematics or the everyday contexts and hence labelled either as expressive or public domain. The tables I and II below summarises this discussion.

Table I: Shows the Domains of actions

\begin{tabular}{|l|l|l|l|}
\hline \multicolumn{2}{|c|}{} & \multicolumn{2}{|l|}{ Contents (signifieds) } \\
\cline { 3 - 4 } \multicolumn{2}{|c|}{$\begin{array}{l}\text { Expressions } \\
\text { (signifiers) }\end{array}$} & Strong classification & Weak classification \\
\cline { 2 - 4 } & Weak classification & Expressive & Pescriptive \\
\hline
\end{tabular}

Source: Adapted from Dowling (1998, p. 133)

Further development led to a modified scheme presented in Table II shown below.

Table II: Shows the edited table of Domain of actions

\begin{tabular}{|l|l|l|l|}
\hline \multicolumn{2}{|c|}{} & \multicolumn{2}{|l|}{ Conten ts (signifieds) } \\
\cline { 3 - 4 } \multicolumn{2}{|c|}{} & I+ & I- \\
\hline Expressions (signifiers) & I+ & Esoteric & Descriptive \\
\cline { 2 - 4 } & I- & Expressive & Public \\
\hline
\end{tabular}

Source: Adapted from Dowling (2007, 2008, 2009)

Dowling (1998) contented that the form of expression and nature of the content can be measured separately either in terms of strength of classification (Dowling, 1998) or in terms of the degree of institutionalisation (Dowling, 2007). What has been modified in Table II is the term 'classification', which is replaced by the term institutionalisation (signified by I). As in Table I, where distinction is made in terms of strength of classification, in Table II the distinction is made in terms of the strength of institutionalisation (indicated by '+' (strong), and weak by '-'. Concepts displayed in both tables suggest a range of strategies that could be deployed in terms of mathematics teaching, and in analysing of mathematics texts. These domains (Esoteric, Descriptive, Expressive, and Public) suggest that in a written or spoken text, one can look at the manner in which a text is tuned or organised. This can be in terms of the nature of the metaphors used or contexts fetched (signifiers), and determining to what practices these refer (signified) (Hakadiva-Vatileni, 2016). The concept of classification (see in Table I) refers to the strength of the insulation between the two categories (that is, The Everyday and the Mathematics). Dowling (1998, p. 116) indicated that the term classification can be used to measure the degree of specialisation of any social category, while the term institutionalisation is used to distinguish between texts that deploys exclusively technical mathematical signs, and texts that deploying signs where expression and content are arbitrary with respect to mathematics"(Dowling, 2007, p. 6). "Those regions of the practice for which expression and content are most strongly institutionalised (I+) form what we might regard as the non-negotiable part of school mathematics, and I refer to this as the esoteric domain of the practice"(Dowling, 2008, p. 3).

A text that is not couched in esoteric domain language (neither its expression nor content are strongly institutionalised language), but look far more like everyday language, is what is termed as public domain language (Dowling 2008). Here, both text expression and content are weakly institutionalised (I-). The descriptive domain employs a mathematical language that refers to nonmathematical content. In other words, it describes another practice (such as backing activity) in mathematics terms. Dowling refers this to the language of mathematical modelling, and the prime site of the myth of reference. The expressive domain deploys non-mathematical language to refer to mathematical content, and this is what Dowling $(2008$, p. 4) termed as the "domain of pedagogic metaphors". Examples commonly used in the teaching of Mathematics are a fraction as a piece of cake, an equation as a balance, greater than, less than, and equal to as crocodile mouth, folded arm, bird's mouth and so forth.

Ways in which students can be assisted to get access to mathematics has also been a concern to some researchers and policy documents. In South Africa for example, there has been a commitment to make school mathematics not only more accessible, but also more relevant for students (Nyabanyaba, 1999). As a result, curriculum in South Africa sought to make learning more integrated and more 'relevant and connected to real-life situations'; and this commitment inspired researchers to develop a better and more critical understanding of the issue of 'relevance' or 'reallife contexts' in school mathematics (Nyabanyaba, 1999, p. 10). Among some of the research findings are that some tasks that summons the everyday "requires students to engage partly as though a task were real whilst simultaneously ignoring factors that would be pertinent in the 'real life version' of the task (Boaler, 1993, p. 14). An example is the observation made by Cooper and Dunne (1997) in the examination item in which students were asked to work out the number of times a lift that can carry a maximum of 14 people would have to go up and down in order to carry 269 people to the top floor. The duo argued that such items ignores real-life issues such as the choices peoples makes. For example, the possibility that some people might choose to use the stairs rather than wait for the lift.

Although many argue for including contexts from everyday practices, "some are suspicious of the potential to create a bridge between everyday practices and formal, academic mathematics through the use of contextualized tasks (Jablonka, 2008 , p. 10). Furthermore, Jablonka (2008) maintained that when confronted with such tasks, students usually faces dilemma as to whether they should make extensive or only little reference to their everyday knowledge. Other researchers 
attempted to interpret the roles of schools in mathematics education and scrutinized concepts involved in the topic of relevance (concepts such as real-life, utility or usefulness, and contexts), and that scrutiny led them to identify tensions that exist between knowledge and experience acquired in and out of school, that this is not topics of mathematics (Carraher \& Schliemann, 2002).

In terms of interpretations and classroom practice, Godfrey. Sethole (2004) found out that 'because of teachers' different experiences and the different values they place on the everyday in mathematics, they handle the incorporation of the everyday quite differently". Godfrey. Sethole (2004, p. 18) argued that the practical experiences of mathematics teacher participants provided insight into some of the practical challenges teachers had to negotiate in order to provide legitimacy for the everyday in mathematics. This indicates that although incorporating the everyday is a desirable aspect of mathematics education, it is also a challenging and demanding one. Likewise, in her study, Hakadiva-Vatileni (2016) found out that the sense mathematics teachers made of the curriculum statement that promotes meaningfulness in mathematics were divergent, and the their practices that attempted to bridge school mathematics and the everyday were ad hoc and not uniform.

\section{Ways mathematics teachers teach comparisons of numbers}

There are about three observed ways in which teachers who attempt to take on board the notion of incorporating the everyday into the mathematics, teach comparison of numbers. These ways incorporate the use of metaphors such as crocodile mouth, folded arm, and the bird's beak. For explication purposes, these phrases will be used as strategy names: The crocodile mouth, folded arm, and the bird's beak strategy. Though in different ways, observed student teachers attempted to accommodate the two discourses, namely mathematics and the everyday. Due to their own different experiences, and perhaps different values they place on the everyday in mathematics, they handle the incorporation of the everyday differently. In all cases, the purposeful activity of Mathematics casts a gaze beyond itself. First, the descriptions of the three strategies will be presented and discussion follows after.

\section{A. The crocodile mouth strategy}

In this strategy, Teacher $A$ gave a scenario of a hungry crocodile that lives in a river near Rundu town beach. According to this scenario, the crocodile always watches villagers who come to swim, or at times draw water from the Okavango River. The crocodile always opens its mouth to the side where there are lots of swimmers, or people who came to withdraw water. Using the similar scenario in a separate incident, Teacher B told her learners, a story of villagers who come to feed a crocodile in the Okavango River. In the story there was a boy who sits at the river bank and was always amused by the crocodile behavior once it sees villagers bringing baskets of feed. Each day the boy comes to the river to watch the crocodile actions. Like Teacher A, Teacher B informed the learners that the crocodile mouth always opens up towards the direction of large number of feeders, where there more baskets of feed, or where there is a basket with more feed. The teacher used the picture on the right.

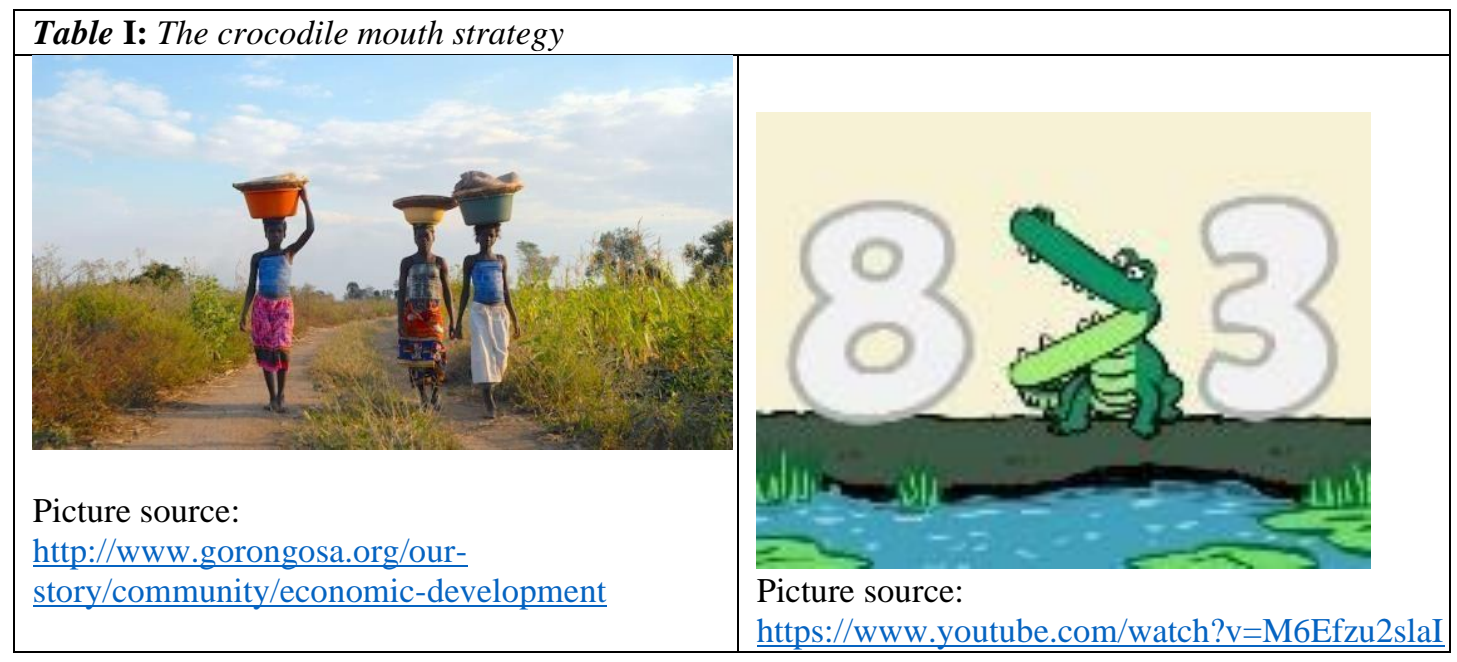

When there are equal number of swimmers on the either side of the river bank, the crocodile get confused and it keep its mouth closed.

\section{B. The elbow or bend arm strategy}

In this strategy, Teacher $\mathrm{C}$ uses both of his arms or his single arms to demonstrate Greater than $(>)$ and Less than $(<)$ relationship signs. The teacher bent both of her arms in an upward or downward direction to demonstrate a less than, and a greater than relationship sign (refer to Table II). He used both arms to demonstrate an equal sign. Apart from demonstrating with his arm, no arm picture was used. 


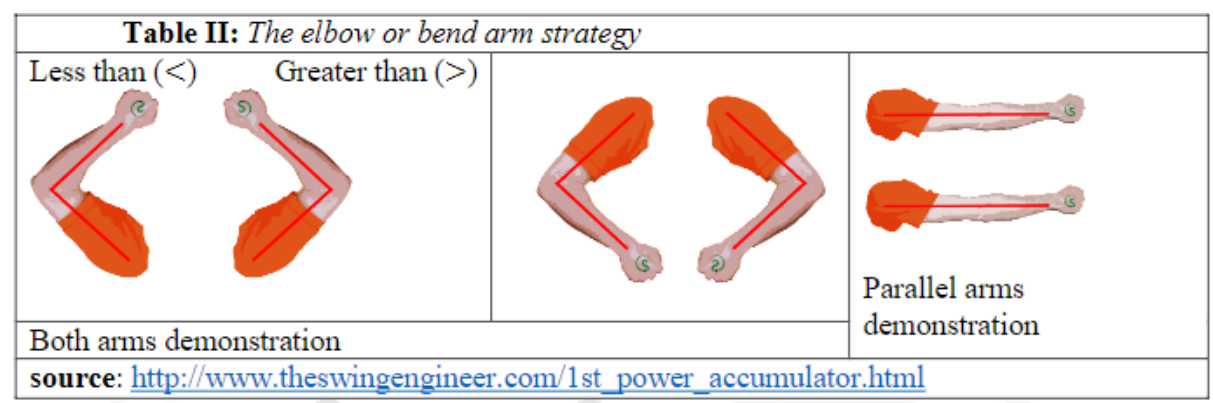

\section{The bird's Beak strategy}

In this strategy, Teacher D used an example of a bird's beak. No teaching aid was brought in the class, whether that of a model of a bird or a picture (iconic mode). The teacher told the learners that an open beak demonstrates greater than $(>)$, but unlike the strategy Teacher A and B employed (the Crocodile mouth), Teacher D did not indicate direction of the bird's mouth, nor did she mention that the mouth of a bird always opens towards the most feed. For the purpose of explication, the pictures in Table III are used.

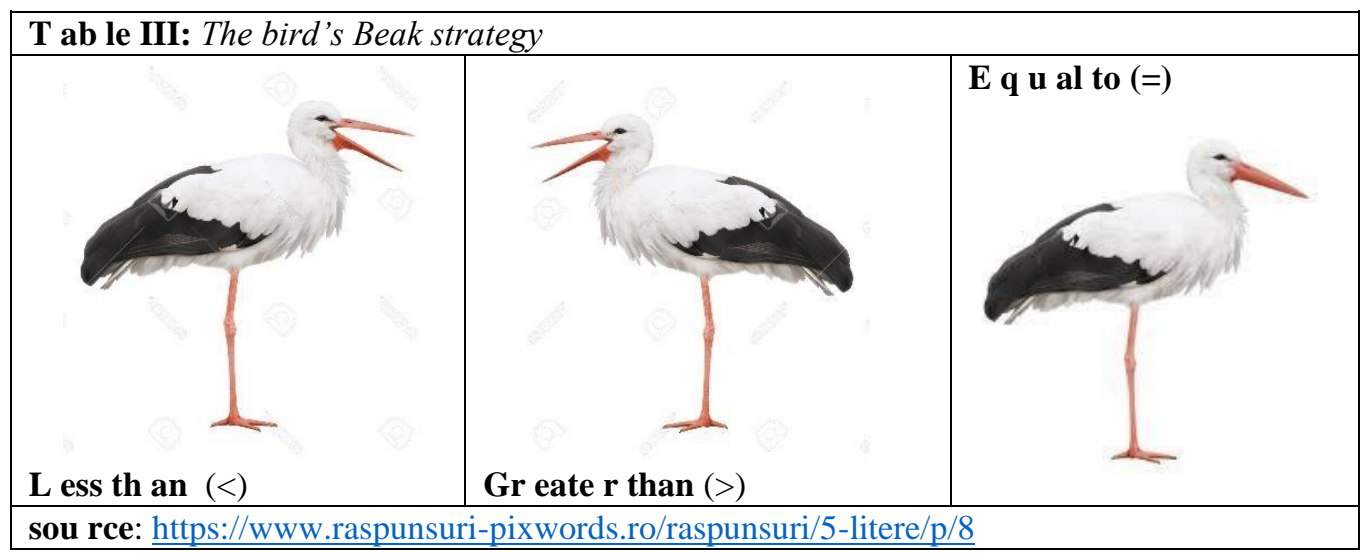

\section{Use of Relationship sign}

In another example, Teacher E used relationship signs and tell the student to note the size of each end as shown below.

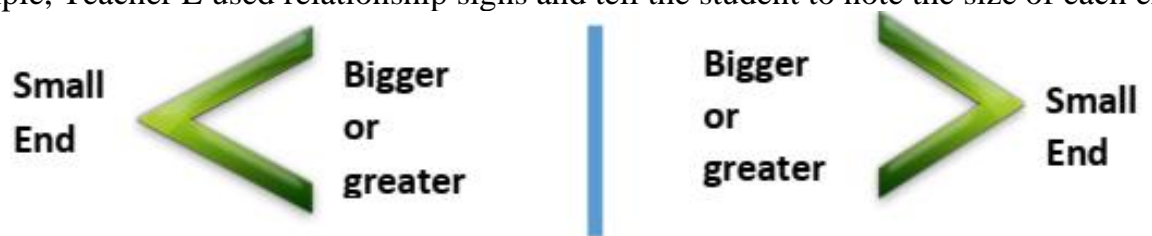

Figure 1: Shows different sizes of the two ends of a relationship sign (i.e. a less than \& greater than sign.

bers and use the two sides or ends of a e 2 below:

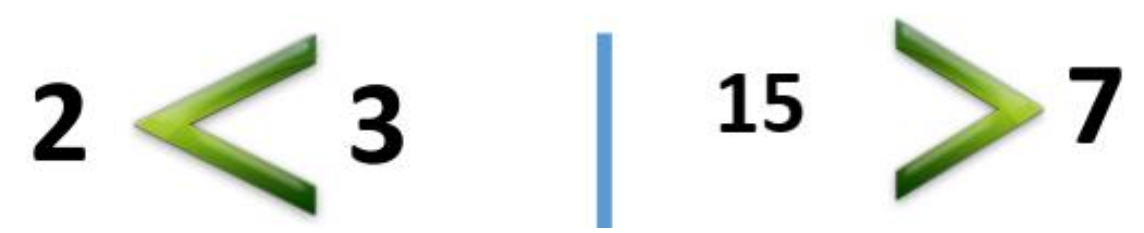

Figure 2: This figure uses the sizes of the two ends of the relationship sign to compare whole numbers.

Making sense of the three ways of in corporating the everyday in the Mathematics employed by teachers A. The crocodile mouth strategy

All these teachers did their best to draw from the everyday while teaching comparison of numbers. In the crocodile strategy, Mathematics casts a gaze on the "everyday" and recontextualised an activity of swimmers and a starved crocodile' mouth into mathematics. Teachers A used a context of swimming activity which could speaks more to learners' experience, particularly those living near the river. Those that lives at places where water gathers, and people could swim in could perhaps relate with the scenario. Teachers B recontextualised an activity of village crocodile feeders and a crocodile's mouth. Both of these contexts helps facilitate the learning of relationship signs. Taking note of this story, learners could score correct answers by inserting the right relationship sign. Teacher B provided three alternatives: That those crocodile feeders might come individually, or as a group of two or more. One could say that Teacher B tried to relate to the everyday as compared to Teachers A. While the context used by Teacher B facilitates the learning of mathematics relationship signs, it is a dead-mock reality (Godfrey Sethole, Goba, Adler, \& 
Vithal, 2006) since it is unlikely that there exist a crocodile that is fed by villagers in the Okavango River. Dead mock reality implies that the mathematics "made reference to the Everyday in a way which is highly unlikely or impossible"(Godfrey Sethole et al., 2006, p. 125) Secondly, considering view, the crocodile might not able to see how much feed in a basket particularly if it is not full to the brim.

Additionally, one could also say although this utterance and the written text that followed deploys exclusively technical mathematical signs (greater than, less than and equal to ), at the same time this utterance or text deployed signs where expression and content are arbitrary with respect to mathematics. That is, swimming, crocodile feeding are not mathematics activities, but these are everyday activities that can possibly use mathematics to optimize its own activities. The crocodile mouth in this scenario is a pedagogic metaphor that is used to refer to the mathematics technical terms of greater, bigger than and equal to. Hence both Teacher A and B operated in the expressive domain (the domain of pedagogic metaphors).

\section{B. The elbow or bend arm strategy}

The teacher in this example did not mention any activity to which he was making reference to nor did he use any picture while presenting her lesson. The teacher only demonstrated with his arms. However, if the teacher used the provided pictures in his presentation, one could assume that Teacher C probably made reference to Golfers' activity of Muscle Power Accumulator. Muscle Power Accumulator is simply the bending and straightening of the right arm (for right handed golfers). This Teacher $\mathrm{C}$ just did a demonstration without mentioning the specific everyday activity, this indicates that when incorporating the everyday in Mathematics, teachers may not always be explicit as to what context or activity is drawn in. One could also argue that contexts drawn in mathematics may be implicit. Similar to the examples given by Teacher A and Teacher B, this context could work well for learners' learning of relationship signs irrespective of whether the specific reference is made to an Everyday activity. Similarly, the teacher operated in the expressive domain (the domain of pedagogic metaphors).

Considering these learners ages and their reasoning abilities, it might be worth investigating what children reasons would be like if Teacher $\mathrm{C}$ demonstrate with one arm points downward while the other point upwards ( see Table IV below). This may test their eye coordination as well.

\begin{tabular}{|l|}
\hline T ab le IV: The opposite directed arms \\
\hline \\
Less than $(<$ \\
Pemonstrating with both arms pointing in opposite direction \\
http://www.theswingengineer.com/1st_power_accumulator.html \\
\hline
\end{tabular}

\section{The bird's Beak strategy}

The activity of birds opening their mouths could be a familiar example to most children if not to all. However the fact that Teacher D did not indicate direction of the bird's mouth (e.g. open beak pointing towards the left-hand side, or righthand side), and neither did she mention that the mouth of a bird always opens towards the most feed, could put learners in a dilemma. Like any other animal, a bird can point to any direction with its mouth open. Since it can point to any direction, learners could ask the Teacher $\mathrm{D}$ to give more details to the scenario. This means that a teachers needs scrutinize the context or metaphor, and needs to provide this context more and specific details before he starts using it in the lesson. The teacher needs to consider in advance, what types of questions are likely to arise during the lesson. Having taken this into consideration, one could conclude that individual teachers may not always be in a position to design everyday or 'real life -based' contexts for mathematics learning. Likewise, they may not always be in a position to predict for their students, how mathematics should be learnt through the use of everyday contexts.

Likewise, Teacher $\mathrm{C}$ operated in the domain of Pedagogic metaphors, the expressive domain. This is because, the bird's beak is used to represent $>,<$ and $=$.

\section{The use of Relationship signs app roach}

For the explication purposes, Figure 1 and Figure 2 are copied down here below. Considering Figure 1, the teacher used everyday terms of 'Bigger than' and 'smaller than to label and compare the two ends of a relationship sign. Here, the beginning of Teacher E's utterance appear to have begun in a public language, hence operating under the Public Domain. Although the teacher appear to have used everyday terms of 'Bigger than' and 'smaller than', these very same terms are the one used as name used for the two relationship signs in mathematics. This suggest utterances used in the esoteric domain to name the two relationship signs. 


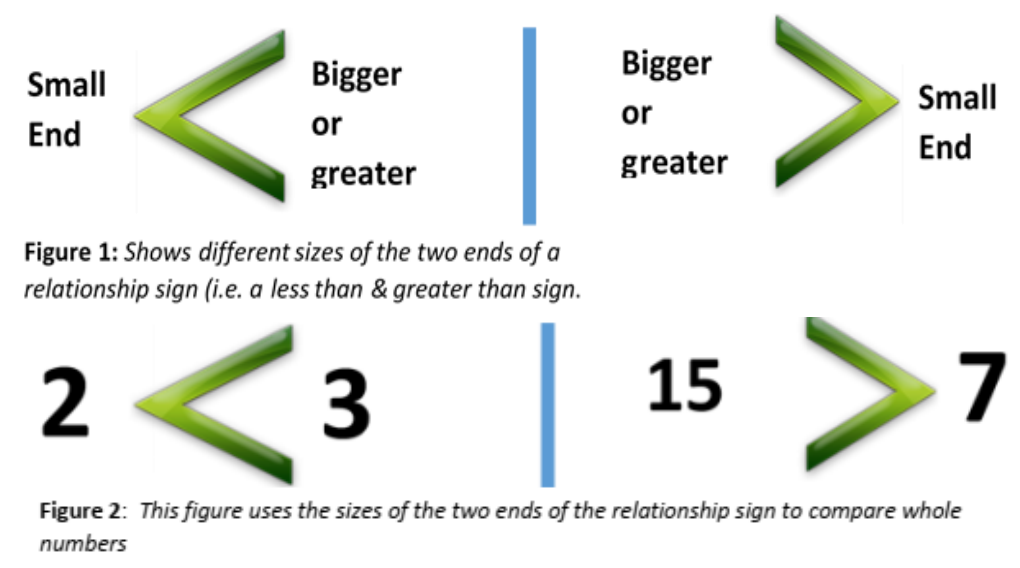

Furthermore, Figure 1 depicts the explanation that translated in Figure 2. In Figure 2, one could see pure mathematics objects (i.e. 2, 3, 7, 15, < and >). A technical language that is both written and spoken is mathematical. In other words, there is a strong institutionalization of text both in terms of its expression, and what is being referred to or described here is mathematics. Teacher E could be classified as having taught under the umbrella of the esoteric domain.

\section{Conclusion}

In this paper, the author attempted to compare and analyse three different strategies teachers used to teach comparison of whole numbers, as well as their ways of helping their students establish the meaning of relationship signs $(>,<$, and $=$ ) in mathematics. All these teachers attempted to operate from the expressive domain as they present their lessons. All strategies that the teachers used could facilitate the learning of relationship signs. However, it is also indicated that the beak metaphor could do a similar job if the teacher provided further specific details to the scenario. From the way teacher D presented the scenario of a bird's beak, it is concluded that individual teachers may not always be in a position to design everyday 'real life' contexts for mathematics learning, and that they may always not be in a position to predict for their students, how specific topics in mathematics should be learnt through the use of everyday contexts. The paper also concluded that when incorporating the everyday in the mathematics, the contexts that teachers use or draw from and recontextualise into the mathematics are not always explicitly everyday activities.

\section{References}

[1].Arcavi, A. (2002). The everyday and the academic in mathematics. Journal for Research in Mathematics Education, $11,12-29$.

[2].Boaler, J. (1993). 'The role of contexts in the mathematics classroom: do they make mathematics more "real"?'. For the Learning of Mathematics, 13(2), 12-17.

[3].Carraher, D. W., \& Schliemann, A. D. (2002). Is everyday mathematics truly relevant to mathematics education? In J. Moshkovich \& M. Brenner (Eds.), Everyday and Academic Mathematics in the Classroom. Monographs of the Journal for Research in Mathematics Education (Vol. 11, pp. 238283).

[4].Cooper, B., \& Dunne, M. (1997). Testing National Curriculum mathematics: some critical comments on the treatment of 'real' contexts for mathematics'. The Curriculum Journal, 3(3), 231-244.

[5].de Abreu, G., \& Crafter, S. (2016). Mathematics learning in and out of school: Towards continuity and discontinuity. In Lyn D. English \& David Kirshner (Eds.), Handbook of International Research in Mathematics Education (3 ed., pp. 295-415). New York, London. : Routledge.

[6].Dowling, P. (1998). The Sociology of Mathematics Education: Mathematical myths/Pedagogic texts. London: Falmer.

[7].Dowling, P. (2007). Organising the Social. Philosophy of Mathematics Education Journal, 21, 1-27.

[8].Dowling, P. (2008). Mathematics, myth and method: The problem of alliteration.(1-22). Retrieved from http://www.pauldowling.me/publications/dowling2008a.pdf

[9].Dowling, P. (2009). Sociology as Method: Departures from the forensics of culture, text and knowledge. Rotterdam: Sense.

[10]. Hakadiva-Vatileni, F. N. (2016). The Academic and the Everyday: Subject Advisors' and Teachers' Interpretations and Classroom Practices Related to the Goal of Connecting School Mathematics and Students' Everyday Experiences in Namibia. (Doctoral thesis), Kings College London, United Kingdom.

[11]. Jablonka, E. (2008). The Everyday and the Academic in the Mathematics Classroom: Confrontation or Conciliation? Paper presented at the The Perspectives on mathematical knowledge, Proceedings of Madif6: The 6th Swedish Mathematics Education Research seminar, Stockholm.

[12]. Ministry of Basic Education Sport and Culture [MBESC]. (2008). The National Curriculum for Basic Education. Okahandja: National Institute for Educational Development (NIED) Retrieved from http://www.nied.edu.na/images/National\%20Curriculum\%20for\%20Basic\%20Education\%20Jan 10.pdf.

[13]. Ministry of Education [MoE]. (2010a). Junior Secondary Phase Mathematics Syllabus: grade 8-10 including

[14]. Additional Mathematics Grade 9-10. Okahandja: National Institute for Educational Development (NIED).

[15]. Ministry of Education [MoE]. (2010b). Mathematics Syllabus Grade 5-7: Upper Primary Phase. Okahandja: 
National Institute for Educational Development (NIED).

[16]. Ministry of Education [MoE]. (2015). Mathematics Syllabus Grades 4 - 7: Senior Primary Phase. Okahandja: National Institute for Educational Development (NIED)

[17]. Nyabanyaba, T. (1999). Whither Relevance? Mathematics Teachers' Discussion of the Use of 'Real-Life' Contexts in School Mathematics. For the Learning of Mathematics, 19(3), 10-14.

[18]. Palm, T. (2006). Word Problems as Simulations of Real-World Situations: A Proposed Framework. For the Learning of Mathematics, 26(1), 42-47. doi:10.2307/40248523

[19]. Sethole, G. (2004). Meaningful contexts or dead mock reality: Which form will the everyday take? Pythagoras, 59(June), 18-25.

[20]. Sethole, G. (2005). From The everyday, through The inauthentic, to Mathematics: Reflection on the process of teaching from contexts. In H. L. Chick \& J. L. Vincent (Eds.), Proceedings of the 29th Conference of the International Group for the Psychology of Mathematics Education (Vol. 4, pp. 169-175). Melbourne: PME.

[21]. Sethole, G., Goba, B., Adler, J., \& Vithal, R. (2006). Fine-tuning a language of description for mathematics items which incorporate the Everyday. In D. Clarke, C. Keitel, \& Y. Shimizu (Eds.), Mathematics Classrooms in Twelve Countries: The Insider's Perspective (pp. 117-130). Rotterdam: : Sense.

[22]. Treffers, A. (1987). Three Dimensions. A Model of Goal and Theory Description in Mathematics Instruction - The Wiskobas Project. Dordrecht, The Netherlands: Reidel Publishing Company. 